\title{
Study of the Dependence Effectiveness of Low-potential Heat of the Ground and Atmospheric Air for Heating Buildings from Climatic parameters
}

\author{
Gregory P. Vasilyev ${ }^{1}$, Marina V. Kolesova ${ }^{1}$, Victor F. Gornov ${ }^{1}$, Igor A.Yurchenko ${ }^{1}$ \\ ${ }^{1}$ JSC "INSOLAR-INVEST", Russia, 121433, Moscow, Filevskaya Street, house 32, building 3
}

\begin{abstract}
The article represents the results of researches for division into districts of the territory of Russia and Europe by efficiency of using for the heat supply of buildings of low-potential thermal energy of ground and free air and their combination. While modeling of the heat regime of geothermal HPS in climatic conditions of different regions of the territory of Russia, the influence has been taken into account of the long-term extraction of geothermal heat energy on the ground heat regime as well as the influence of phase transitions of pore moisture in ground on the efficiency of operation of geothermal heat-pump heat-supply systems. While realization of the division into districts, the sinking of temperatures of ground massive was been taken into account which has been called by long-term extraction of the heat energy from the ground, and as calculation parameters of the heat energy from the ground, and as calculation parameters of ground massive temperatures, the ground temperatures were used which are waited for the 5 -th year of operation of geothermal HPS.
\end{abstract}

\section{Introduction}

The climatic characteristics of countries of the Central and North Europe which together with USA and Canada are the main regions of using of low-potential heat energy of the earth determine mainly the need for heating; the air cooling even in the summer period requires relatively rarely Therefore, in contrast to USA, the heat pumps in European countries operate mainly in the heating regime. The USA the heat pumps are used more often in air heating systems combined with ventilation, what allows both to heat and to cool the outdoor air In European countries the heat pumps are usually used in water heating systems $[1,5]$.In climatic conditions of the territory of Russia, one of the most perspective and everywhere accessible sources of lowpotential energy for heat-pump heat supply systems (HPS) is the ground of surface layers of the Earth. It is known that the operation of the HPS, using the heat from the soil, usually associated with a decrease in the heating season temperature potential recoverable heat from the ground. In this case, for the systems of collection of low-potential ground heat energy using the effect of zero screen negative temperatures of heat energy of place transitions of pore mouisture in ground. At the same time during the heating period repeatedly observed temperature above the temperature of the extracted heat from the ground: the periods of thaw, transitional periods, the periods of the heating season, in which the temperature exceeds temperature recoverable heat from the ground.The works are known for extradition of the efficiency of application of HPS for the climatic conditions of Europe and USA [2,3].

\section{Materials and methods}

As to the climatic conditions of the Russian Federation, the authors of this article have already conducted the estimation of the efficiency of using the geothermal HPS [4], but at its conduction the air HPS and HPS with the combined source of low-potential heat energy"ground+air» are not considered.In the researcher presented in this article, as the criterion of efficiency of application of the heat-pump heat-supply systems was taken the climatological factor $D H_{h p s}$, numerally presenting the quantity of degree-hours of using HPS in one year. This parameter of degree-days or degreehours of the heating period, but takes into account the influence of climatological parameters on the energy transformation factor in HPS. The important moment is the independence of the offered climatological factor on the heat-shield and other characteristic of a building. In the common case the climatological factor DHhps 
may be determined according to following formula degree-hours.

$$
D H_{h p s}=\left(\mathrm{T}_{k}-273-\mathrm{h}_{t}-\mathrm{t}^{c p} H\right) \times \mathrm{Z} \times\left(\mathrm{T}_{k}-\mathrm{T}_{u}\right) /\left(\mathrm{T}_{k} \times \eta\right)
$$

$T_{k}$-heat-transfer agent at the outlet from HPS and index to the heating system, $\mathrm{K}$; ht-temperature head between the heat-transfer agent at the index to the heating system and the inside air; thcp-the mean for the heating season, or operation period HPStemperature of outdoor air, is taken according to SNIP «building climatology» [2]; z-duration of the heating season or operation period of HPS in a year is taken according to SNIP «building climatology» [2]; Ti-the mean temperature of the heat sours of low potential for the heating season or for the period of operation of HPS, K. Is taken according to SNIP «building climatology» [2] as equal to: -for geothermal HPS with vertical heat borehole -taken equal to the average annual temperature of free air increased by 1 degree; -for air systems-mean for the heating season or the operation period -to the air temperature; -for combined systemsto mean for the operation period of each from the sources of low-potential heat energy.

The mean value of «n» was taken for ground as 0.469914 , for air as 0.33652 .The values of «n» are represented in conformity with the data of EN 14511 for the considered regimes. The rest from the used values $\left(\mathrm{H}, \mathrm{z}, T_{u}\right)$ are represented in SNIP 23-01-99 «building climatology» [2]. The division into districts was conducted for two values $T_{k}=308$ and 323 (35 and 50 0C). These values reply to the standart design regimes for the heat-pump system fixed by the European norms EN 14511. The value $T_{k}=308 \mathrm{~K}$ corresponds to the floor and air heating systems. The value it is taken equal to 15 degrees for $T_{k}=3008 \mathrm{~K}$ and to 30 degrees for $\mathrm{T} 1=323 \mathrm{~K}$. From the output according to the formula the values held zoning by climatological factor. The source of low-potential heat energy is: ground, air and ground+air (fig.1-3). The construction of the maps was conducted for all the regional centeres of Russia in the program MapInfo Professional 10.5.

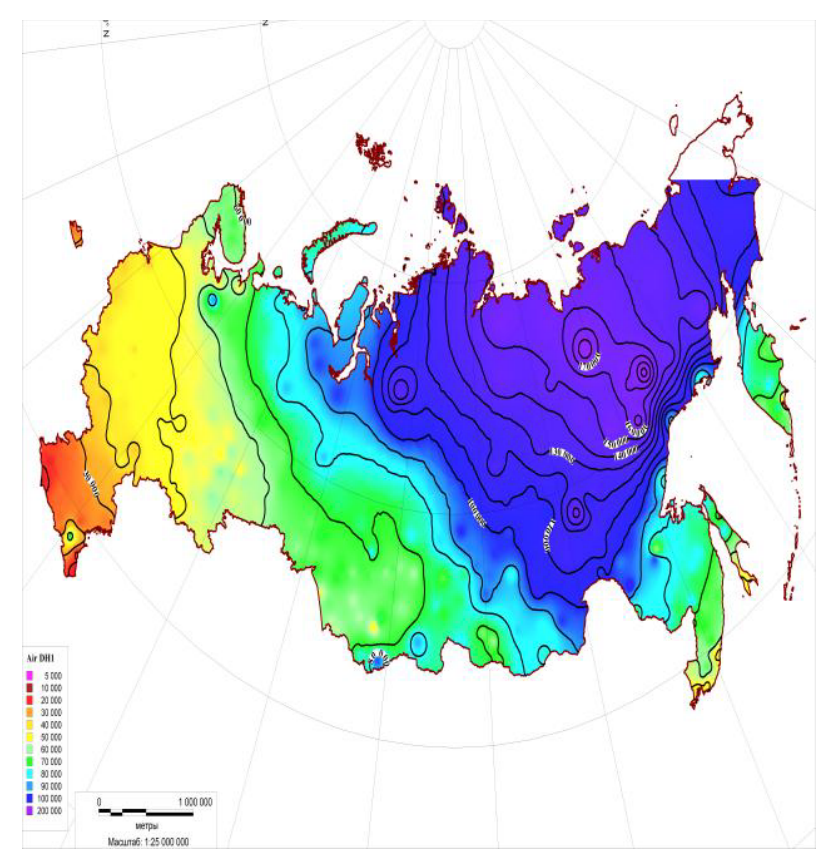

Figure 1. Division into districts for $\mathrm{Tk}=308 \mathrm{ht}=15$ degrees. Source of low-potential heat energy is air

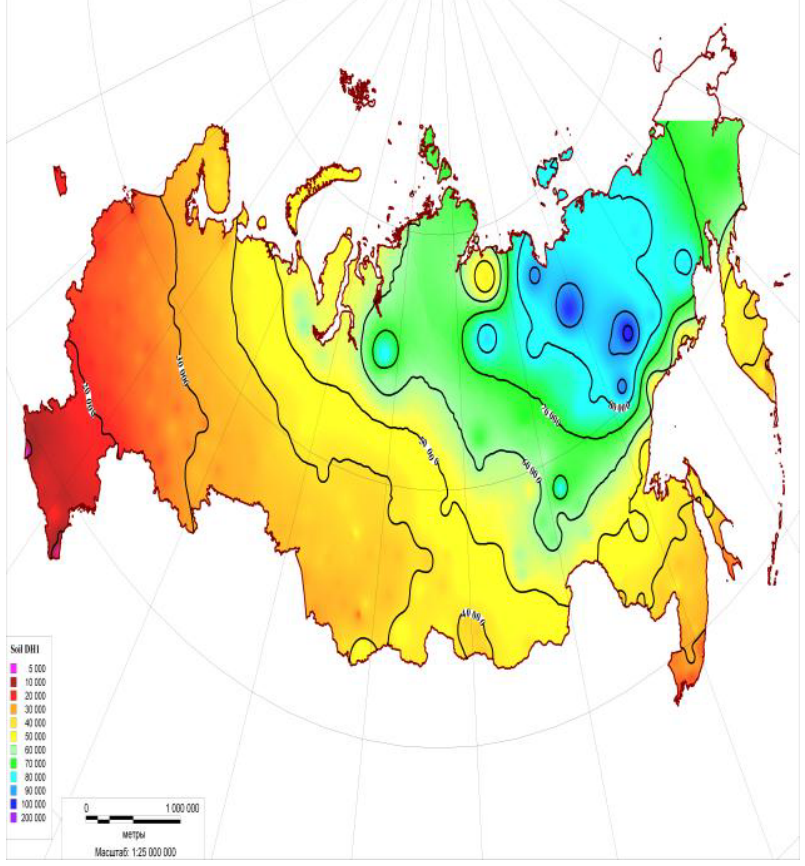

Figure 2. Division into districts of the territory of Russia for $\mathrm{Th}=308 \mathrm{Ht}=15$ degree. Source of low-potential heat energy is ground 


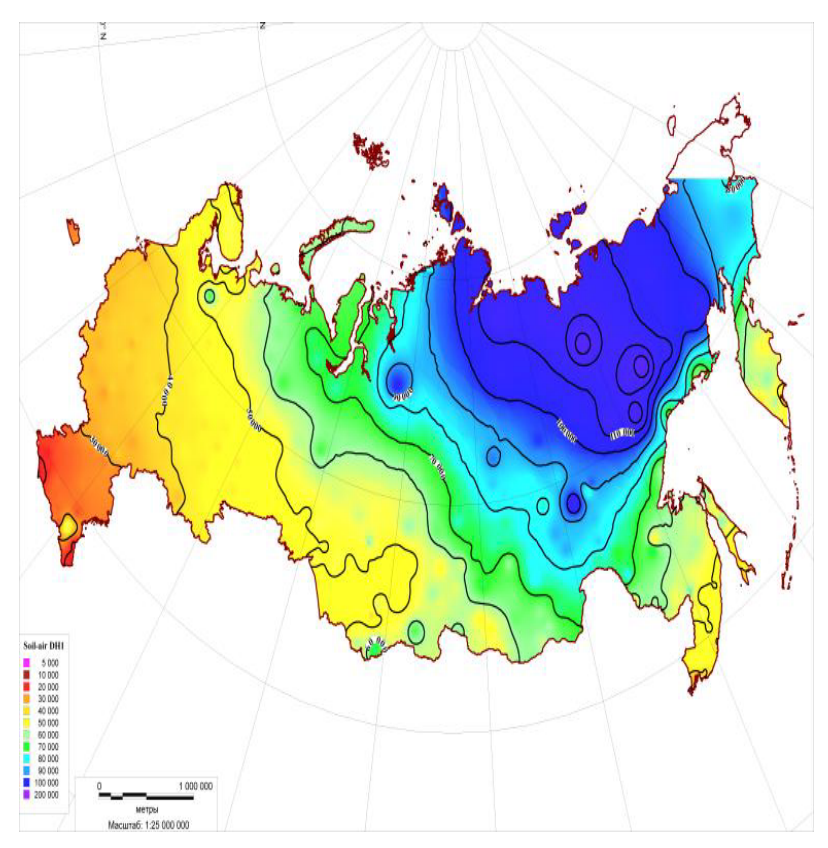

Figure 3. Division into districts for $T_{k}=308 \mathrm{Ht}=15$

degrees. Source of low-potential heat energy is combination air+ground

The result of the calculation was obtained climatological factor, thanks to which you can define criteria of efficiency of various heating systems for each region of Russia and any country in the World. In order to obtain the value of factual consumption of the energy by the heat pump system for the aims of heating and ventilation it is necessary the specific characteristic of expenditure by the building of the heat energy for heating and ventilation defined, for example, SP50.13330.2012 «Heat Protection of Buildings» $W /\left(\mathrm{m}^{2^{*} \circ} \mathrm{C}\right)$, to multiply by the climatological factor $D H_{h p s}[5]$.

\section{Conclusions}

The analysis of the results of the conducted numeral experiments allows to do the conclusion that in the climatic conditions of Moscow and the South zone of Russia the utilization as the low-potential heat sources for evaporators of the heat-pump equipment of the developedenergy complex of free air in combination with ground is very effective. The energy economy at the application of this solution is from $13 \%$ in climatic conditions of Moscow up to $20 \%$ for the South regions of Russia.

An important peculiarity of the obtained results of researches is the possibility of their application in the mass housing, cottage and commercial building. Today tens of thousands of buildings andcommercial objects (shopsand others) are equipped with conditioning systems operated in the winter time in the heat pump regime and heating apartments. But the operation of air conditioners in this regime is physically possible and economically effective only up to temperatures of free air higher then minus $15{ }^{\circ} \mathrm{C}$. At lower temperatures airconditioning off and actually required backup heating system. The technical solutions elaborated in the limits of this article allow this problem to solve also at the expense of switching ever at low temperatures of free air to another source of low-potential heat energyground of superficial layers of the Earth.

As a result the elaborated intellectual heat pump energy complex will be able to effectively be operated the whole year round in the heating regime and in the conditioning regime. The conducted researches have shown that the switching over in such moments of the heat pump from ground to free air will allow to shorten by $20 \%$ the demanded of heat borehole of the lowpotential heat energy collection system of the ground the cost of which today is equal more than $50 \%$ of the cost of all geothermal heat pump system of heat supply. In this case, more than $15 \%$ economy is provided compared with HPS cost which use also as a low-grade of low potential heat energy only ground.

The obtained data usually show that the efficiency of utilization of ground as a low-potential heat energy in our country is higher than at the utilization of air and the combined utilization of ground + air, but in the South regions of the country these values are practically equal.

\section{Acknowledgments}

The Research was conducted by JSC "INSOLARINVEST" with the financial support of the Ministry of Education and Science of Russia. The unique identifier of the project is RFMEFI57915X0115.

\section{References}

1. Vasilyev G.P. Geothermal heat pump heating systems and its operating efficiency in climate conditions of Russia. // AVOK - 2007. - n.5. - p. 58-68.

2. Climatic Atlas of the USSR. H 1.2. -M., 1960, 1962.

3. Vasilyev G.P. Gornov V.F. Peskov N.V., Kolesova M.V. Burmistrov A.A., Timofeev N.A, Leskov V.A.,Yurchenko I.A. Accounting for "Zero Curtain" Effect in GSHP Simulation. Applied Mechanics and Materials Vol. 664 (2014) pp 243-249.

4. Vasilyev G.P. heating and cooling supplies buildings and structures using low-grade thermal energy of the surface layers of the Earth 
(Monograph). Publishing house "Granitca". M., "Red star" - 2006. - 220 P.

5. Man, Y., Yang, H., Wang, J., and Fang, Z, (2012). In situ operation performance test of ground coupled heat pump system for cooling and heating provision in temperate zone. Applied Energy 2012; 97:913-20.

doi:10.1016/j.apenergy.2011.11.049. 